\title{
Ecological Risk Assessment of Shan Xin Mining Area Based on Remote Sensing and Geography Information System Technology
}

\author{
Chaokui Li ${ }^{1,2,3}$, Jianhui Chen ${ }^{1,2,3}{ }^{*}$, Mengguang Liao ${ }^{1,2,3}$, Guo Chen ${ }^{1,2,3}$, Qinlan Zhou ${ }^{1,2,3}$ \\ ${ }^{1}$ National-Local Joint Engineering Laboratory of Geo-Spatial Information Technology, Hunan University of Science and \\ Technology, Xiangtan, China \\ ${ }^{2}$ Hunan Province Engineering Laboratory of Geospatial Information, Hunan University of Science and Technology, \\ Xiangtan, China \\ ${ }^{3}$ Institute of Geospatial Information Science, Hunan University of Science and Technology, Xiangtan, China \\ Email: chkl_hn@163.com, ${ }^{*} 1689777979 @ q q . c o m$
}

How to cite this paper: Li, C.K., Chen, J.H., Liao, M.G., Chen, G. and Zhou, Q.L. (2018) Ecological Risk Assessment of Shan Xin Mining Area Based on Remote Sensing and Geography Information System Technology. Journal of Geographic Information System, 10, 234-246.

https://doi.org/10.4236/jgis.2018.102012

Received: December 4, 2017

Accepted: April 10, 2018

Published: April 13, 2018

Copyright $\odot 2018$ by authors and Scientific Research Publishing Inc. This work is licensed under the Creative Commons Attribution International License (CC BY 4.0).

http://creativecommons.org/licenses/by/4.0/

\begin{abstract}
In this paper, introducing new remote sensing and geographic information technology to solve the problem of data collection and analysis, this makes the study of ecological risk assessment very quick and accurate. Taking the Shan Xin mining area of the tin mine in Lengshuijiang of Hunan Province as the research object, using the remote sensing image data of three periods in 2005, 2010 and 2015, the remote sensing image is classified carefully and the landscape classification map of the mining area is obtained. The ecological risk index is introduced and the ecological risk values are sampled and interpolated on the ArcGIS platform. The ecological risk spatial distribution map based on the landscape pattern index was obtained. The ecological risk was divided into 5 levels by using the Jenks natural classification method, and each ecological risk grade area was counted. The research results show that: from year 2005 to year 2010, landscape ecological risk trend of the mining area is growing up; the trend rising area of landscape ecological risk is mainly in the southwest and northeast of the Shan Xin mining field; the area of higher and high ecological risk is increasing year by year; and the trend of dispersed development in space is obvious; the development trend of ecological risk in the mining area is rapidly increasing; in 2010 - 2015, the higher and high ecological risk area decrease slightly with the increasing of area of grassland and residential low vulnerability of landscape types; the ecological risk area showed a slow decreasing trend. The research results provide an objective reference for decision making of ecological environment governance.
\end{abstract}




\section{Keywords}

RS \& GIS Technology, Shan Xin Mining Field, Ecological Risk Assessment, Jenks Nature Classification, Risk Index

\section{Introduction}

With the development of Remote Sensing (RS) and Geography Information System (GIS) technology, they are being introduced to the field of ecological risk assessment. The $2 \mathrm{~S}$ (RS and GIS) technology has become a very important technical approach in landscape ecology research. We can obtain spatial data of the study area rapidity by RS technology, especially on a large spatial scale; geographic information system for its powerful spatial data processing ability and analyze ability can be applied to analysis on landscape pattern change; global positioning system can provide accurate geographic coordinate. " $2 S$ " technology changes the research methodology substantially and gradually become tools in the areas of data-collecting, storage, processing and analyzing for landscape ecological studies. Landscape pattern research is one of the key problems of landscape ecology research. Now it has become the focus of global change research [1]. Landscape pattern and its change is a composite reflection of the interaction of natural factors and human activity in certainty regional ecological environment, and the change of landscape pattern also affects on ecological process in the region [2]. So it is an effective method for understanding the status of landscape ecology and its spatial variability to study landscape pattern in mining area by the principle of landscape ecology. Therefore, to study the landscape patterns in mining area according to the principle of landscape ecology provides an effective method for understanding the status of landscape ecology and its spatial variability [3]. Through the dynamic changes of regional landscape pattern to reflect the ecological effects of natural changes and human activities, the ecological environment can be improved by adjusting human behavior and optimizing the allocation of resources, and the sustainable development of the region is realized finally. The disturbance of human activities will inevitably lead to the change of regional landscape pattern, thus affecting the ecological security of regional space. At present, most of the research on ecological risk assessment in mining area is concentrated on the microscopic toxicological risk analysis. From the perspective of landscape pattern change, this paper quantitatively analyzes the ecological risk of mining area with the help of $2 S$ technology, and emphasizes the risk effect of the spatial pattern. The scientific guidance of ecological risk management in mining area with research results is beneficial to evade ecological risk and protect the ecological environment.

In this paper, taking the Shan Xin mining area as the research object, in the support of new $2 S$ technology, from the angle of landscape pattern change, the comprehensive ecological risk index of mining area landscape was constructed, 
and the relative change degree of ecological risk in mining area was reflected through the change of risk index, so as to provide objective decision basis for ecological environment protection, governance and management of mining area.

\section{Method of Ecological Risk Assessment}

\subsection{Evaluation Method}

In this paper, the Google Earth images in the year of 2015 and the SPOT5 remote sensing images in the years of 2005 and 2010 are used as the data source. Spatial resolution of SPOT5 is $2.5 \mathrm{~m}$; spatial resolution of Google is $0.6 \mathrm{~m}$, the temporal for June to September. During this time, various vegetation grow well, this is beneficial to use growth characteristics to distinguish different plant covered including farmland, forest land and grassland and other land. Since the acquisition of SPOT data with rectification of SAR images and atmospheric correction, hence simply geometric rectification for data according to topographic map of 1/10,000 scale of Xi Kuang Shan mining area of 1/10,000 scale. Google Earth images geometric corrected according to SPOT5 remote sensing images of 2010. Finally, each image should be clipped separately, then collect remote sensing of the area to complete data preprocessing. In order to ensure the accuracy of interpretation, other data, including GPS field survey data, could be put in.

\subsection{Creation Landscape Ecological Risk Index}

LESA (Landscape Ecological Risk Assessment) means analysing the influencing degree of some interference sources such as human activities and natural disasters and etc from the corner of landscape structure ,pattern evolution or landscape ecological process [4] [5] [6]. Popular methods include ecological loss degree index evaluation method、landscape ecological pattern index evaluation method [7] [8] [9], this paper established an landscape ecological risk index according to ecological loss degree index evaluation method, and calculate ecological risk values in each sample region on the base of relevant literature and analysis related landscape index. The main index formula is as following:

1) Index of interference degree $\left(E_{i}\right)$.

$$
E_{i}=a C_{i}+b N_{i}+c D_{i}
$$

where: $C_{p} N_{p} D_{i}$ is degree of fragmentation, separation and dominance of landscape $i$ respectively, (see Resources) [10] [11]. $a, b, c$ is the weight of each index, $a+b+c=1$, these 3 indicators reflect the effects of human activities on ecosystem to a certain extent .Judging from the findings of many scholars' study [12] [13], valuation these three indicators as $0.5,0.3,0.2$ respectively.

2) Index of Vulnerability degree $\left(F_{\mathrm{i}}\right)$.

The ecosystems represented by different landscapes play different roles in the maintenance of biodiversity and ecological functions, and also have different resistance against external interference and disturbances. This difference is mainly related to different development phases of these ecosystems during natural succession. 
According to the characteristics of the natural succession stages of various landscapes, the 10 types of landscape are assigned from high to low according to the relevant research results: water $=6$, farmland $=5$, grassland $=4$, woodland $=$ 3 , (dump, mining, mineral yard and tailing storeroom $)=2$, (mining road and essential area $)=1$, then normalized to obtain each vulnerability degree $\left(F_{j}\right)$.

3) Ecological risk index $(E R I)$.

$$
E R I=\sum_{i=1}^{n} \frac{S_{k i}}{S_{k}} \cdot\left(E_{i} \cdot F_{i}\right)
$$

where: $S_{k i}$ is the area of landscape $i$ in sample region $k, S_{k}$ is the total area of sample region $\mathrm{k}, E_{i} \cdot F_{i}$ is loss index of landscape $i, n$ is the number of landscape type.

In order to study the spatial variation of ecological risk, it is necessary to make the ecological risk index spatialization. Considering landscape ecology, the best scale of sampling area is $2-5$ times of the average patch area [12], this study uses $0.4 \times 0.4 \mathrm{~km}$ square to carry out spatial sampling in the study area, a total of 145 sample areas. According to the landscape ecological risk index formula, the comprehensive ecological risk value of each sample area was calculated, which was used as the center value of the sample area.

\section{Experiments and Results Analysis}

\subsection{Study Area}

Hunan Leng Shui Jiang tin mine is located in Leng Shui Jiang mining township, tin mine street office, is the famous "world antimony capital", the geographical coordinate was determined to be $27^{\circ} 31^{\prime} 53^{\prime \prime}$ degrees north latitude and $111^{\circ} 42^{\prime} 35^{\prime \prime}$ degrees east longitude. Mining field have a wide reach which is about $18 \mathrm{~km}^{2}$ (Figure 1), and an exploitation history of over 100 years, the industry of dressing, smelting and mining is highly developed. Tin production has ranked first in China and output accounts for the 1/3 of nationwide total output. After a long time of mining and smelting, some common phenomena, such as surface subsidence, large arsenic-alkali residue deposited may be seen anywhere, caused the plants to die, the heavy metals pollution and the serious pollution of groundwater resources, resulted in obviously degeneration of ecosystem function, seriously affecting the daily life of the local people, and also affected local economic development.

\subsection{Data Processing}

Landscape classification mainly with reference to the "ecological environment of national mineral resources development zone ten years changes in the investigation and evaluation" norms, the development of mineral resources are subdivided into regional features, mining road dump, mineral yards and cultivated land, grassland, woodland, tailings, settlements, water and mining field a total of 10 categories, application the artificial visual interpretation method for remote sensing interpretation. 


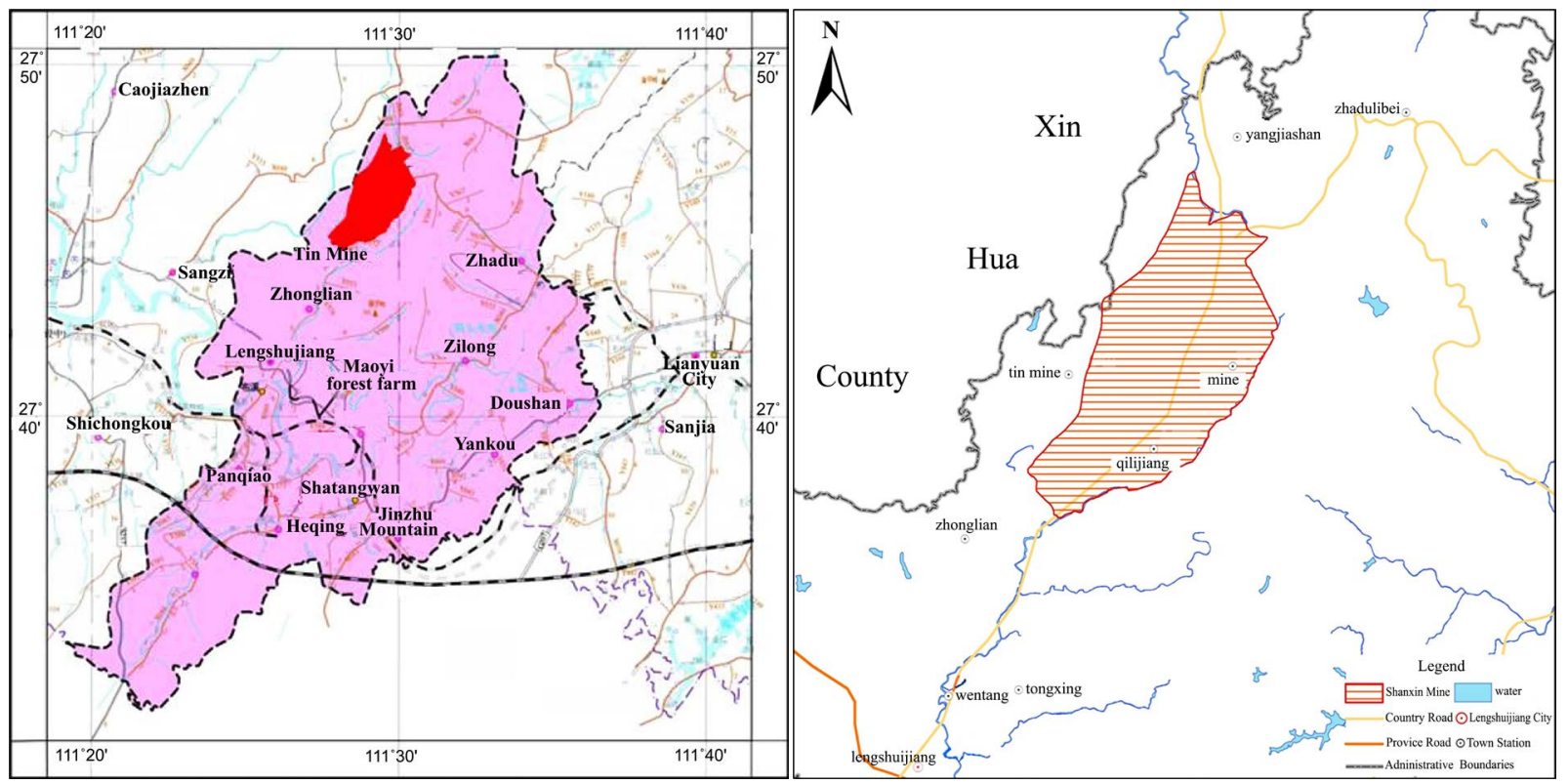

Figure 1. Geographic location and traffic map of the Shan Xin mining area.

On the basis of the result of remote sensing image interpretation and the analyses of landscape type (Figure 2, Table 1), the main landscape region of the Shan Xin mining area is grassland, it takes up more than $40 \%$ of the total area. During 2005 to 2010, the main part of the increased area of the landscape is composed of mining road and mining area; the increasing proportion is $44 \%$ and $13.6 \%$ individually. The landscape area of mineral piling, dump, woodland and residential area has also increased to varying degrees. The main reason is that the increase of mining activities has led to the increase or expansion of the number of mining sites, so as to meet the transportation needs of mining areas and speed up the construction of mine roads. To reduce the size of the landscape of farmland, grassland and water, disorderly development of the mining production area occupied a lot of farmland and grassland, which is one of the main reasons for the decrease of the water in the study area, which mainly exists in the form of a puddle and the pond, the water landscape is vulnerable to human activities influence become extremely fragile.

In the past 2010-2015 years, the area increased obviously with grassland and residential area, and the area of mining field increased slightly. The main areas of area reduction include soil dumping, mineral storage and tailings, and the decrease of woodland and arable land, and the continuous reduction of water landscape. The main reason is that from the beginning of year 2010, the tin mine accelerated the mine ecological environment governance, for some of the waste dump and tailings to carry out vegetation greening governance; the mining industry also carried out rectification work, on the basis of the original work and strengthen the integration of resources and, at the same time, banning illegal indiscriminate mining enterprises; grassland and residential area increased significantly, indicates that with the ecological environment governance work, more 


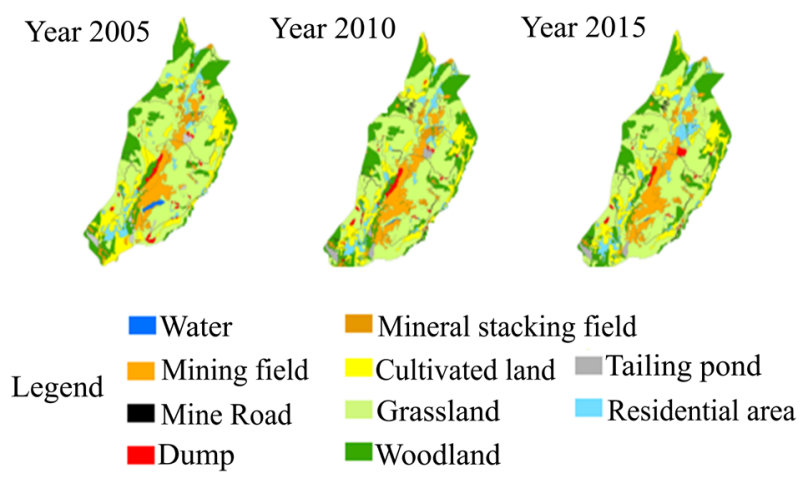

Figure 2. Landscape classification of mining area in 2005 and 2010.

Table 1. Area of landscape types in mining area.

\begin{tabular}{ccccccc}
\hline \multirow{2}{*}{ Type } & \multicolumn{2}{c}{2005} & \multicolumn{2}{c}{2010} & \multicolumn{2}{c}{2015} \\
\cline { 2 - 7 } & area $\left(\mathrm{hm}^{2}\right)$ & scale $(\%)$ & area $\left(\mathrm{hm}^{2}\right)$ & scale $(\%)$ & area $\left(\mathrm{hm}^{2}\right)$ & scale (\%) \\
\hline Mining road & 20.87 & $1.16 \%$ & 30.12 & $1.67 \%$ & 27.92 & $1.55 \%$ \\
Mine Dumping Sites & 26.49 & $1.47 \%$ & 26.86 & $1.49 \%$ & 21.32 & $1.18 \%$ \\
Mineral piled field & 33.57 & $1.86 \%$ & 38.61 & $2.14 \%$ & 10.35 & $0.57 \%$ \\
Farmland & 255.04 & $14.14 \%$ & 231.86 & $12.85 \%$ & 225.76 & $12.51 \%$ \\
Grassland & 836.16 & $46.35 \%$ & 809.03 & $44.84 \%$ & 848.82 & $47.05 \%$ \\
Woodland & 355.48 & $19.7 \%$ & 364.82 & $20.22 \%$ & 359.18 & $19.91 \%$ \\
Tailing pond & 25.9 & $1.44 \%$ & 25.72 & $1.43 \%$ & 15.46 & $0.86 \%$ \\
Residential area & 75.76 & $4.2 \%$ & 86.15 & $4.77 \%$ & 104.55 & $5.80 \%$ \\
Water & 10.3 & $0.57 \%$ & 3.36 & $0.19 \%$ & 2.26 & $0.13 \%$ \\
Mining area & 164.63 & $9.13 \%$ & 187.67 & $10.4 \%$ & 188.39 & $10.44 \%$ \\
\hline
\end{tabular}

suitable for the construction of the land to be developed, and the living environment gradually improved, a substantial increase in grassland can be certain achievement of ecological environment reflects the governance side of mine.

\subsection{Landscape Ecological Risk Index}

Based on the landscape classification map of 2005, 2010 and 2015 three years, according to above Formulas (1) and (2), Fragstats landscape index software and Excel were used to calculate the landscape ecological risk index, and all kinds of landscape ecological risk index in 2000, 2010 and 2015 were obtained (Table 2).

From year 2000 to year 2010, the largest fragmentation index for mining road, road construction often leads to other plaque segmentation, promote the fragmentation of landscape, the landscape connectivity decreased and the 5 years of its fragmentation was reduced. The description of the road construction in mining area is mainly based on the original road widening, instead of a network expansion rate is greater than the growth rate of plaque area increased; except the tailings, mining and mineral dumps in the landscape fragmentation index did not change significantly, other landscape types increased in different degree, that 
Table 2. Landscape ecological risk index in 2005-2015.

\begin{tabular}{|c|c|c|c|c|c|c|c|}
\hline year & type & $\begin{array}{l}\text { Fragmentation } \\
\text { index }\end{array}$ & $\begin{array}{l}\text { Separation } \\
\text { index }\end{array}$ & $\begin{array}{l}\text { Dominance } \\
\text { index }\end{array}$ & $\begin{array}{l}\text { Interference } \\
\text { index }\end{array}$ & $\begin{array}{l}\text { Loss degree } \\
\text { index }\end{array}$ & ERI \\
\hline \multirow{10}{*}{2005} & Mining road & 12.412 & 19.376 & 0.386 & 11.197 & 0.400 & \multirow{10}{*}{0.026} \\
\hline & $\begin{array}{l}\text { Mine Dumping } \\
\text { Sites }\end{array}$ & 0.642 & 4.806 & 0.083 & 1.329 & 0.095 & \\
\hline & $\begin{array}{l}\text { Mineral piled } \\
\text { field }\end{array}$ & 0.506 & 4.626 & 0.075 & 1.051 & 0.075 & \\
\hline & Farmland & 0.106 & 3.416 & 0.247 & 0.232 & 0.041 & \\
\hline & Grassland & 0.029 & 1.864 & 0.423 & 0.136 & 0.019 & \\
\hline & Woodland & 0.098 & 3.608 & 0.316 & 0.218 & 0.023 & \\
\hline & Tailing pond & 0.347 & 9.136 & 0.059 & 0.923 & 0.066 & \\
\hline & Residential area & 0.436 & 13.530 & 0.139 & 0.729 & 0.026 & \\
\hline & Water & 0.971 & 20.694 & 0.046 & 2.451 & 0.525 & \\
\hline & Mining area & 0.146 & 0.955 & 0.147 & 0.292 & 0.021 & \\
\hline \multirow{10}{*}{2010} & Mining road & 9.495 & 11.924 & 0.381 & 8.401 & 0.300 & \multirow{10}{*}{0.040} \\
\hline & $\begin{array}{l}\text { Mine Dumping } \\
\text { Sites }\end{array}$ & 0.931 & 3.954 & 0.091 & 1.670 & 0.119 & \\
\hline & $\begin{array}{l}\text { Mineral piled } \\
\text { field }\end{array}$ & 0.492 & 2.398 & 0.090 & 0.983 & 0.070 & \\
\hline & Farmland & 0.138 & 0.518 & 0.262 & 0.277 & 0.049 & \\
\hline & Grassland & 0.049 & 0.166 & 0.467 & 0.168 & 0.024 & \\
\hline & Woodland & 0.184 & 0.477 & 0.369 & 0.309 & 0.033 & \\
\hline & Tailing pond & 0.156 & 1.651 & 0.042 & 0.581 & 0.042 & \\
\hline & Residential area & 0.650 & 1.845 & 0.180 & 0.914 & 0.033 & \\
\hline & Water & 4.170 & 23.671 & 0.043 & 9.195 & 1.970 & \\
\hline & Mining area & 0.112 & 0.519 & 0.162 & 0.244 & 0.017 & \\
\hline \multirow{10}{*}{2015} & Mining road & 9.456 & 12.359 & 0.371 & 8.510 & 0.304 & \multirow{10}{*}{0.036} \\
\hline & $\begin{array}{l}\text { Mine Dumping } \\
\text { Sites }\end{array}$ & 0.750 & 3.984 & 0.065 & 1.583 & 0.113 & \\
\hline & $\begin{array}{l}\text { Mineral piled } \\
\text { field }\end{array}$ & 1.063 & 6.805 & 0.053 & 2.583 & 0.185 & \\
\hline & Farmland & 0.102 & 0.451 & 0.244 & 0.235 & 0.042 & \\
\hline & Grassland & 0.045 & 0.154 & 0.484 & 0.165 & 0.024 & \\
\hline & Woodland & 0.153 & 0.438 & 0.359 & 0.280 & 0.030 & \\
\hline & Tailing pond & 0.129 & 1.943 & 0.023 & 0.652 & 0.047 & \\
\hline & Residential area & 0.478 & 1.436 & 0.177 & 0.706 & 0.025 & \\
\hline & Water & 3.545 & 26.614 & 0.029 & 9.762 & 2.092 & \\
\hline & Mining area & 0.122 & 0.541 & 0.165 & 0.256 & 0.018 & \\
\hline
\end{tabular}


mining area 5 years overall landscape fragmentation trend; the separation index is consistent with the change from the fragmentation index; the dominance index, showed that the grassland landscape in landscape in the mining area, the dominant degree is relatively increased, grassland and cultivated land; The increase of the loss index of woodland increases the ecological loss of the landscape type and increases the ecological risk in human disturbance.

From year 2010 to year 2015, in addition to mineral dumps and mining field landscape fragmentation index increased, the landscape types have different degrees of reduction, indicating that the overall fragmentation degree of mining area has slowed; separation index, cultivated land, woodland, grassland and mining field did not change significantly, showed that the more concentrated distribution of these types of landscape, a landscape stability good; grassland is the dominant landscape in this area is still 5 years; from the loss index, the biggest change for landscape water, showed a sharp increase trend, showed that the landscape pattern in the mining area, vulnerable to external interference and cause serious ecological damage, high ecological risk; cultivated land, forest land and grassland landscape damage the index has a smaller decline, it is showed that the ecological risk decreased.

General speaking, the comprehensive ecological risk index (ERI) of the mining area in 2005 is 0.026 , but increased to 0.040 by year 2010, and was reduced to 0.036 by year 2015 . In the past 10 years, the ecological risk index has increased and dropped two trends. Although nearly 5 years, to carry out governance and mine production management of the ecological environment, to a certain extent reduces the ecological risks in some areas, but compared with 2005, the overall ecological risk still present growth trend, ecological risk situation is still very serious.

\subsection{Spatial Distribution of Landscape Ecological Risk}

145 ecological risk in the sample area are respectively calculated a by using Formula (1) and (2). Get experimental variation function by way of GS + geostatistics software, to fitting theoretical semivariogram, sphere model to fit the best in 2005 and 2010, Gaussian model to fit the best in 2015. This ordinary Kriging interpolation method is used to spatial interpolation to Landscape ecological risk on ARCGIS, and the Spatial Distribution Maps of ecological risk in 2005, 2010 and 2015 (Figure 3) are obtained. This paper uses Jenks natural classification, this Landscape ecological risk is divided into5 degree to analyze feature of 3 Landscape ecological risk, since during such many years the ecological risk index is standing at between 0.022 and 0.078. It includes: low ecosystem risk area $(0.022<\mathrm{ERI}<0.033)$, lower ecosystem risk area $(0.033<\mathrm{ERI}<0.039)$, medium ecosystem risk area $(0.039<\mathrm{ERI}<0.045)$, higher ecosystem risk area $(0.045<$ ERI $<0.054)$, high ecosystem risk area $(0.054<$ ERI $<0.078)$, and statistics area of each degree by Arc GIS (Table 3).

From Figure 3 and Table 3, we can that: the most part of Shan Xin mining 
Table 3. Area of different grade ecological risk.

\begin{tabular}{cccc}
\hline Degree & 2005 & 2010 & 2015 \\
\hline low ecosystem risk area $(0.022,0.033]$ & $58.91 \%$ & $29.82 \%$ & $44.92 \%$ \\
lower ecosystem risk area $(0.033,0.039]$ & $34.16 \%$ & $25.86 \%$ & $31.67 \%$ \\
medium ecosystem risk area $(0.039,0.045]$ & $4.77 \%$ & $26.80 \%$ & $13.60 \%$ \\
higher ecosystem risk area $(0.045,0.054]$ & $1.47 \%$ & $13.57 \%$ & $8.40 \%$ \\
high ecosystem risk area $(0.054,0.078]$ & $0.70 \%$ & $3.95 \%$ & $1.42 \%$
\end{tabular}
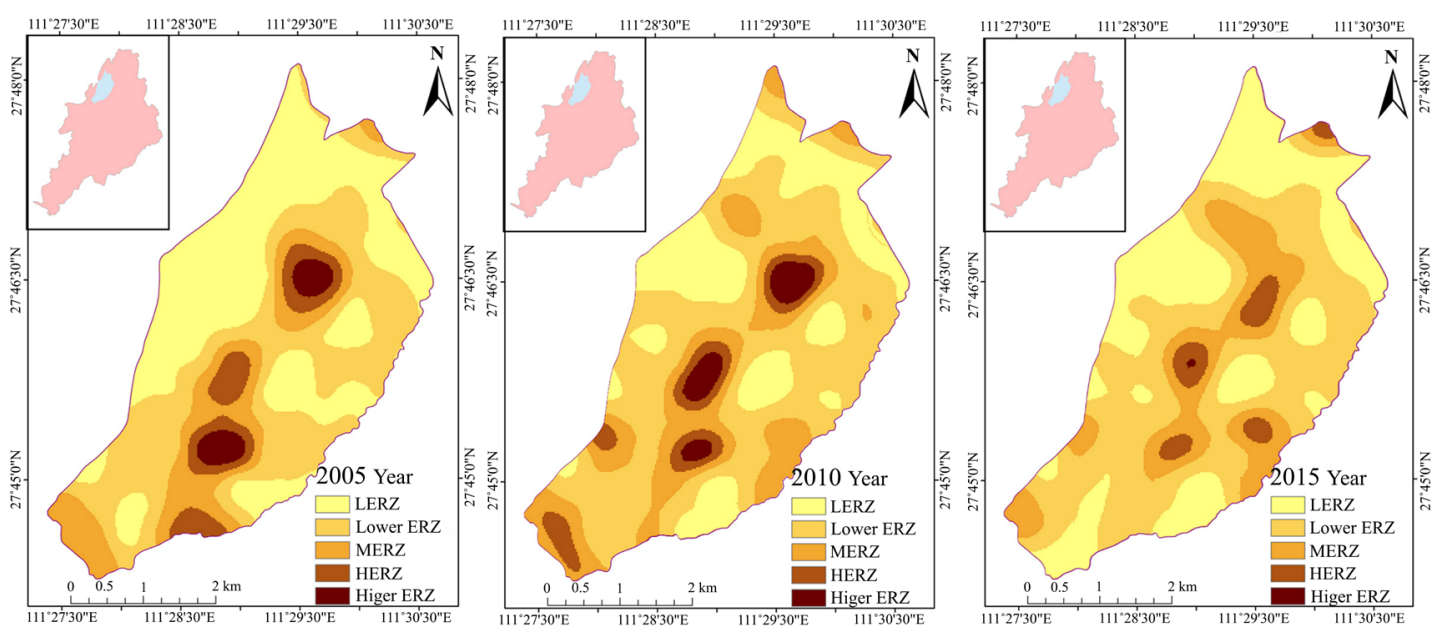

Figure 3. Spatial distribution of ecological risk in mining area in 2005, 2010, 2015.

area is low ecosystem risk area or lower ecosystem risk area, cover $93.07 \%$ of mining area, distributed mainly over The north, the northwest and the Southeast of Shan Xin mining area, this major landscape type is grassland and woodland; the area of higher or high ecosystem risk was quite limited, only $2.17 \%$, distributed mainly over South, this major landscape type is water and mining area. Outside interference is easy to cause serious loss of ecological damage for water, which lead the landscape ecosystem risk is high. Medium and higher ecosystem risk areas are mainly distributed in high ecosystem risk area outer ring.

In 2010, the landscape ecosystem risk pattern of Shan Xin mining area changed dramatically, low and lower ecosystem risk area have declined dramatically, only $55.68 \%$ of total .higher and high ecosystem risk area increased quickly, grow to $13.57 \%$ and $3.95 \%$ respectively. According to Figure 3, there's a lot more area in the northwest in mining area transmuted into higher or high ecosystem risk area, so does the Southeast, the main reason is the major landscape of these 2 part is farmland, the vulnerability degree is high and intensive meets woodland, grassland and residential area, that's increased the partial fragmentation and ecological risk. During the 5 years, higher and high ecosystem risk area have a sharp increase and distribution scattered. It's the Disorderly development of mining area which is increasing ecosystem risk in mining area.

With the development of the ecological environment governance in 2010, 
higher and high ecosystem risk area has decreased, from $17.52 \%$ to $9.82 \%$ in 2010 to 2015 . The proportion of medium ecosystem risk area has also fallen to $13.20 \%$. Through consolidation in mining area and green the mine dumping sites ground, woodland, grassland and farmland inclined to integrate ,landscape fragmentation index was decreased, which means ecological environment has been somewhat improved by environmental protection. Above all, ecological risk in mining area increases quickly and then shows a slowly declining tendency based on mining landscape ecological risk index and spatial variation from year 2005 to year 2015.

\subsection{Discussion of Change Trend}

In order to further analyze the changing trend of all kinds of landscapes, Arc GIS was applied to analyze the three phase remote sensing interpretation maps of the tin mine in the period of 10 years, and the change moment of landscape types was generated, as shown in Table 4. In order to facilitate the analysis of data, transportation land, dumping ground, mineral storage yard and mining field are classified as mineral facilities. From Table 4, we can see that from 2005 to 2010 10 years ago, with the expansion of mining area and the establishment of new mineral facilities, a large number of grassland, woodland and arable land were occupied. At the same time, the problems caused by the geological disasters caused by the production activities have a serious impact on the residential housing in the mining area. From the perspective of the characteristics of the turning out, the mineral facilities are mainly turned out to be grasslands, which are transferred from the dump. The reason is that there is no management for the waste dump and the soil pollution is serious. Only a few herbaceous plants can survive, so they are gradually transformed into barren grassland. In the past 2005-2010 years, the main trend of landscape change is the transformation of grassland and woodland into mineral facilities.

The same method is used to generate the landscape type transfer matrix of the 2010-2015 mining area, such as Table 5. It can be seen from Table 5 that, compared with the previous 5 years, the transformation activities between the various landscape types are relatively weak. From the features of the mining facilities, the largest area of the mine is the tailings reservoir, which is mainly converted into a dump. The mining area reused the tailings pond which had been disused and transformed it into a dump. It not only made the land resources to be maximally utilized, but also played a protective role in the ecological environment, which brought huge economic benefits to the flash mining area. From the features of mineral facilities, mineral facilities are mainly transferred to grassland and residential areas, mainly by dumping ground and mineral storage sites. The implementation of the mine restoration project can gradually eliminate the impact of production and development on the ecological environment of the mining area. The dump and mineral dumps and other mineral production facilities with land reclamation and vegetation restoration, improve the land quality; at the same time for the reuse of waste mineral facilities, soil restoration 
Table 4. 2005-2010 transfer matrix of landscape type in mining area.

\begin{tabular}{|c|c|c|c|c|c|c|c|c|c|c|}
\hline Type & $\begin{array}{l}\text { Mine } \\
\text { land }\end{array}$ & $\begin{array}{c}\text { Traffic } \\
\text { land }\end{array}$ & Dump & $\begin{array}{c}\text { Mineral } \\
\text { stacking } \\
\text { field }\end{array}$ & $\begin{array}{c}\text { Cultivated } \\
\text { land }\end{array}$ & $\begin{array}{l}\text { Grass } \\
\text { land }\end{array}$ & $\begin{array}{l}\text { Wood } \\
\text { land }\end{array}$ & $\begin{array}{l}\text { Tailing } \\
\text { pond }\end{array}$ & $\begin{array}{l}\text { Residential } \\
\text { land }\end{array}$ & Water \\
\hline Mine land & 156.21 & 0.12 & 0.40 & 0.62 & 0.69 & 3.70 & 1.64 & - & 0.65 & 0.12 \\
\hline $\begin{array}{l}\text { Traffic } \\
\text { land }\end{array}$ & - & 20.75 & - & - & 0.05 & - & - & - & - & - \\
\hline Dump & 1.10 & - & 15.88 & 0.03 & 0.56 & 8.48 & 0.05 & - & - & 0.20 \\
\hline $\begin{array}{l}\text { Mineral } \\
\text { stacking } \\
\text { field }\end{array}$ & 0.37 & - & - & 28.99 & 1.24 & 1.24 & 0.24 & - & 1.54 & 0.01 \\
\hline $\begin{array}{c}\text { Cultivated } \\
\text { land }\end{array}$ & 0.53 & 0.75 & 2.01 & - & 190.33 & 36.71 & 16.87 & 0.67 & 6.46 & 0.09 \\
\hline Grass land & 23.91 & 6.69 & 5.23 & 4.20 & 27.36 & 734.22 & 26.95 & 0.87 & 7.41 & 0.01 \\
\hline Woodland & 3.79 & 1.36 & 2.57 & 2.91 & 7.54 & 12.71 & 316.93 & 3.03 & 4.92 & 0.14 \\
\hline $\begin{array}{l}\text { Tailing } \\
\text { pond }\end{array}$ & 0.87 & - & - & 1.74 & - & 1.72 & 0.39 & 21.06 & - & - \\
\hline $\begin{array}{l}\text { Residential } \\
\text { land }\end{array}$ & 1.16 & 0.18 & 0.61 & 0.01 & 3.71 & 3.39 & 1.33 & - & 65.53 & - \\
\hline Water & - & - & - & 0.02 & - & 7.38 & - & - & - & 2.91 \\
\hline
\end{tabular}

Table 5. 2010-2015 transfer matrix of landscape type in mining area.

\begin{tabular}{|c|c|c|c|c|c|c|c|c|c|c|}
\hline Type & $\begin{array}{l}\text { Mine } \\
\text { land }\end{array}$ & $\begin{array}{c}\text { Traffic } \\
\text { land }\end{array}$ & Dump & $\begin{array}{c}\text { Mineral } \\
\text { stacking } \\
\text { field }\end{array}$ & $\begin{array}{l}\text { Cultivated } \\
\text { land }\end{array}$ & $\begin{array}{l}\text { Grass } \\
\text { land }\end{array}$ & $\begin{array}{l}\text { Wood } \\
\text { land }\end{array}$ & $\begin{array}{l}\text { Tailing } \\
\text { pond }\end{array}$ & $\begin{array}{l}\text { Residential } \\
\text { land }\end{array}$ & Water \\
\hline Mine land & 183.85 & - & - & - & - & 4.10 & - & - & - & - \\
\hline Traffic land & - & 27.92 & - & - & - & 1.91 & - & - & - & - \\
\hline Dump & 0.69 & - & 14.34 & - & 0.63 & 9.30 & 1.07 & - & 0.65 & - \\
\hline $\begin{array}{c}\text { Mineral } \\
\text { stacking field }\end{array}$ & 1.87 & - & - & 10.35 & - & 7.86 & 0.92 & - & 17.51 & - \\
\hline $\begin{array}{l}\text { Cultivated } \\
\text { land }\end{array}$ & - & - & - & - & 233.39 & 2.89 & 3.17 & - & 2.03 & - \\
\hline Grass land & 0.48 & - & - & - & - & 795.74 & 13.33 & - & - & - \\
\hline Woodland & 1.49 & - & - & - & 0.75 & 21.12 & 340.69 & - & 0.34 & - \\
\hline Tailing pond & - & - & 6.99 & - & - & 3.18 & - & 15.45 & - & - \\
\hline $\begin{array}{l}\text { Residential } \\
\text { land }\end{array}$ & - & - & - & - & 0.99 & 1.49 & - & - & 84.02 & - \\
\hline Water & - & - & - & - & - & 1.22 & - & - & - & 2.26 \\
\hline
\end{tabular}

and construction of residential land to make full use of resources, create a good living environment for residents. The mine restoration work has gradually improved and improved the quality of life and environmental quality of the residents in the Shan Xin mining area, and promoted the transformation of the local economy and the social development. In the past 2010-2015 years, the main trend of landscape change in the mining area is the conversion of mineral facili- 
ties to grassland and residential areas.

\section{Conclusions}

The ecological risk assessment index of the Shan Xin mining area was studied based on $2 \mathrm{~S}$ technologies, and it gave out the risks assessment results of the Shan Xin mining area. Research achievement provides scientific decision basis for Ecological environment control in mining area. The investigation method gives a good example for similar issue investigation. The main conclusions are as following:

1) According to the change of landscape type, from year 2005 to year 2010, the resource exploitation and economic development in the mining area caused the result that a large number of farmland and grassland was changed into other landscape type. From 2010 to 2015, with the development of mine ecological environment control, the large area restoration of grassland and the rapid growth of residential area in the mining area showed that the mining area's ecological environment management has achieved certain results.

2) In the view of the change of ecosystem risk, in 2005 to 2010, the trend of total ecosystem risk increased quickly. The landscape ecological risk area is mainly located in the southwest and northeast part of the Shan Xin mining area. The areas of higher risk and high risk are increasing year by year, and the ecological spatial distribution shows the trend of dispersed development. From 2010 to 2015 , the areas of higher risk and high risk decreased year by year, and the landscape ecological risk of mining area decreased slowly.

3) The division of the study area is based on the boundary line of the Shan Xin mining area, which does not fully consider the heterogeneity of the landscape space. To a certain extent, it has split the original surface physical geographical connection, and has some interference in the comprehensive analysis of the landscape pattern. The index of ecological risk based on landscape index is not enough to determine the threshold of landscape ecological risk. The construction of the existing landscape ecological risk index only takes into account the landscape structure, and does not take into account other factors such as society and economy. Therefore, the study of the method of determining the risk index of comprehensive factors is the next step to be solved.

\section{Acknowledgements}

This paper is funded jointly by the projects: Nature Science Funding of China (No.: 41571374), the Key Laboratory Open Funding Project of Hunan Province (No.: JL16K01, CT16K02), the Key Research Project of Hunan Education Ministry (No.: 16A070), Nature Science Joint Funding of Hunan Province and Xiangtan Local (No.: 2017JJ4037).

\section{References}

[1] Peng, J., Dang, W.X., Liu, Y.X., et al. (2015) Review on Landscape Ecological Risk 
Assessment. Acta Geographica Sinica, 70, 664-677.

[2] Gao, B., Li, X.Y., Li, Z.G., et al. (2011) Assessment of Ecological Risk of Coastal Economic Developing Zone in Jinzhou Bay Based on Landscape Pattern. Acta Ecologico Sinica, 31, 3441-3450.

[3] Li, Z.-Y., Zhang, N., Tang, J., et al. (2011) Analysis on the Landscape Ecological Risk of Jilin Coal Mining Area. Journal of Jilin University. Earth Science Edition, 41, 207-214.

[4] Pan, Y.J., Wang, Y.L., Peng, J. and Han, Y.N. (2012) Research Progress in Ecological Risk Assessment of Mining Area. Acta Ecologica Sinica, 32, 6566-6574. https://doi.org/10.5846/stxb201110191553

[5] Xin, H.M., Zhang, J., Wang, C.Y. and Fu, J. (2012) An Index Indicating Risk Grade of Natural Hazard for Island Ecosystem Based on Landscape Patterns. Acta Oceanologica Sinica, 34, 90-94.

[6] Tian, Y., Li, B. and Wang, S. (2015) Study on Landscape Ecological Risk of the Coastal Areas of Jiangsu Province. Research of Soil and Water Conservation, 22, 241-245, 251.

[7] Xie, H.L. (2008) Regional Eco-Risk Analysis of Based on Landscape Structure and Spatial Statistics. Acta Ecologica Sinica, 28, 5020-5026.

[8] Wu, J.S., Qiao, N., Peng, J., Huang, X.L., Liu, J.Z. and Pan, Y.J. (2013) Spatial Variation of Landscape Eco-Risk in Open Mine Area. Acta Ecologica Sinica, 33, 3816-3824. https://doi.org/10.5846/stxb201207301083

[9] Li, B.J., Gu, H.H. and Ji, Y.Z. (2015) Study of Spatial-Temporal Change of Land Eco-Risk in Mining Area. Journal of China University of Mining \& Technology, 33, 573-580.

[10] Meng, J.-J. and Zhao, C.-H. (2009) Research Progress on Index System of Regional Ecological Risk Assessment. Chinese Journal of Applied Ecology, 20, 983-990.

[11] Wei, W., Shi, P.-J., Lei, L., Zhou, J.-J. and Xie, B.-B. (2014) Eco-Risk Analysis of Oasis Region Based on Landscape Structure and Spatial Statistics Method-A Case Study of Wuwei and Minqin Oases. Journal of Natural Resources, 29, 2023-2035.

[12] Gong, J., Zhao, C.-X., Xie, Y.-C. and Gao, Y.-J. (2014) Ecological Risk Assessment and Its Management of Bailongjiang Watershed, Southern Gansu Based on Landscape Pattern. Chinese Journal of Applied Ecology, 25, 2041-2048.

[13] Gao, B. (2011) Landscape Pattern Dynamics of Coastal Economic Zone in Jinzhou Bay, Liaoning Province. Shandong Normal University, Jinan. 